\title{
Prednisone on the threshold of rational use in the treatment of rheumatoid arthritis ${ }^{*}$
}

\author{
Doyt L. Conn \\ Division of Rheumatology, Emory University School of Medicine, Atlanta, USA; dconn@emory.edu \\ Received 2 May 2013; revised 2 June 2013; accepted 15 July 2013 \\ Copyright (c) 2013 Doyt L. Conn. This is an open access article distributed under the Creative Commons Attribution License, which \\ permits unrestricted use, distribution, and reproduction in any medium, provided the original work is properly cited.
}

\section{ABSTRACT}

This is a review of the evolution of the use prednisone in the treatment of rheumatoid arthritis (RA). Cortisone was introduced in 1949 and shortly thereafter, the Mayo investigators found that low divided doses with slow tapering were effective and caused fewer side effects. In 1959, a British double blind 2 year study of prednisolone treatment in early RA demonstrated effectiveness and reduced bony erosions. This experience was lost over time and empiricism and efforts to reduce side effects dominated practice for the next 35 years. Since 1995, a number of controlled studies of low single daily doses of prednisone in early RA have been reported by European investigators. They have shown clinical improvement, reduced bony erosions, augmentation of the effect of dmards and few side effects. During the last 25 years, the molecular actions of glucocorticoids have been elucidated. The time relationship of the dose to the biologic and clinical effects has been established. As a result of the information on the diurnal effect of glucocorticoids and the documentation of the effect occurring 5 - 6 hours after the dose and dissipating by 24 hours, a delayed release preparation of prednisone has been developed. With the rediscovery of the effectiveness of low single daily morning dose of prednisone in early RA by controlled studies and the demonstration of the onset and duration of the clinical effect of low dose of prednisone, it is now possible to use low doses of prednisone rationally and effectively in the treatment of RA. It remains to be determined whether a single morning, single evening or a twice a day low dose is the most effective and safe. It is doubtful if the new de-

\footnotetext{
"I have received no financial support for this review.

${ }^{\#}$ I have no conflict of interest.
}

layed release prednisone is any more effective than the usual immediate release prednisone if given at the same time.

Keywords: Prednisone; Rheumatoid Arthritis; Rayos

\section{INTRODUCTION}

It has been a long struggle in the medical community to learn to use prednisone rationally and appropriately in the treatment of rheumatoid arthritis (RA). I will review this difficult journey after the introduction of cortisone in 1949, as physicians empirically, without much knowledge or guidance, used prednisone in the treatment of RA. Frequently, too much was used for too long and then tapered off too quickly without the patient realizing the benefit of prednisone. Today, with knowledge about the molecular mechanisms of action of glucocorticoids, the relationship of dose and time to the beneficial effects and controlled studies showing the effectiveness and safety of low single daily doses of prednisone in the treatment of RA, physicians can use prednisone more rationally and effectively.

On the market is a new prednisone product, Rayos, which is a delayed release prednisone [1,2]. It was designed based on the diurnal effect of glucocorticoids and a signal paper describing the peak effect of low doses of prednisone 5 hours after administration [3,4]. The studies leading to the development of this product have provided important insight into the relationship of dose and time to the onset of and duration of clinical effects.

\section{MATERIALS AND METHODS}

The information used in this paper was obtained by an informed selective search of the literature.

\section{DISCUSSION}

The glucocorticoid story from the beginning has been 
a tale of progress and then regression usually because of lack of knowledge and the reliance on empiricism. It is instructive to review this story. It started with the paper published in the Mayo Clinic Proceedings in April 1949, by Hench and Kendall describing 16 patients with early active RA treated with $100 \mathrm{mg}$ of cortisone acetate given intramuscularly daily. This was a controlled double blind study [5]. With cortisone there was uniform dramatic improvement in the patient's clinical and laboratory measures and an equally dramatic recrudescence of symptoms on reducing or stopping the cortisone. This was received with over-enthusiasm by physicians and the public. Cortisone, then prednisone was FDA approved and with little guidance and few studies it was available by prescription. Frequently the doses used were too high, used too long, and then rapidly tapered, resulting in side effects, transient benefit and physician and public distrust.

Yet there was guidance available for the appropriate use of prednisone in the treatment of RA early on. Several papers by the Mayo group in the 1950s described the effectiveness and relative safety of low divided doses of oral cortisone, then prednisone, in treating RA and they emphasized gradual tapering [6,7]. The reason for the daily divided doses of cortisone and prednisone was the known short half-life of these drugs and the known recurrence of symptoms 8 - 12 hours after the oral dose. The British Research Council, with Prof. E.G. L. Bywaters, conducted a double blind controlled 2 year study in early RA treated with prednisolone, initially $20 \mathrm{mg}$ per day and then slowly tapered, or aspirin as controland was published in 1959. It showed clinical improvement and retardation of joint damage in the prednisolone treated patients [8].

Apparently these papers emphasizing the beneficial effects had little impact on practice because concern about side effects dominated the thought and practice for the next 3 decades. In part this was influenced by a paper by Harter, Reddy and Thorn appearing in the NEnglJMed in 1963 advocating every other day steroid doses to minimize side effects. In this study, 58 patients on long term glucocorticoids were evaluated, most with asthma, only 3 with RA. They demonstrated that a higher dose given every 48 hours did significantly reduce side effects and minimized suppression of the HPA activity. They stated that efficacy was maintained, but only 3 had RA and their outcome was not discussed [9]. This approach caught on.

Rheumatologists, then and now, receive guidance from textbooks of Rheumatology. Here is a sample of some of the recommendations regarding the use of prednisone in RA appearing in textbooks from the 1960's to the early 1990's. In the $7^{\text {th }}$ Edition of "Arthritis and Allied Conditions", 1966, in the chapter on corticosteroid treatment of
RA, the following principles were listed: Glucocorticoidsshould never be the initial agent used in RA. Its use should only be after unhurried trial of conservative treatment, meaning aspirin. They should not constitute the only treatment. They should not be given if any contraindications. If used they did advise low divided doses [10]. In the $8^{\text {th }}$ Edition of "Arthritis and Allied Conditions", 1972, the idea of a single am dose or an alternate day dose were advocated to limit the effect on the HPA [11]. The pyramid treatment scheme appeared in the $9^{\text {th }}$ Edition, 1979, and in the pyramid, glucocorticoid use was at the top of the pyramid, thus they should be withheld until almost everything else had been tried. When used, prednisone, $7.5 \mathrm{mg}$ per am was suggested to minimize the effect on HPA [12]. In the $2^{\text {nd }}$ Edition of the "Textbook of Rheumatology", 1985, the author stated that prednisone may be used for severe active progressive RA (primarily for the wage earner). He advised 5 $7.5 \mathrm{mg}$, am dose, to minimize HPA suppression [13]. The $4^{\text {th }}$ Edition of "The Textbook of Rheumatology", 1993, discussed low dose prednisone as bridge therapy at the initiation of treatment with dmards, primarily methotrexate, to provide anti-inflammatory control until the methotrexate kicked in. A single low dose, 5 - $7.5 \mathrm{mg}$ per day was recommended. The author suggested that the dose given at night might help reduce morning stiffness [14]. Without any good controlled studies examining the use of prednisone in RA, these comments guided the treatment for many rheumatologists. Nevertheless, with the exception of advocating every other day dosing, the recommendations for prednisone use were reasonable, but were hesitant, advocating delay in use and without confidence in their benefit.

In 1995, a paper by Dr. John Kirwan appeared describing a double-blind controlled 2 year study examining the effectiveness of prednisone, $7.5 \mathrm{mg}$ per day versus placebo, in early RA [15]. Clinical effectiveness and less joint damage were demonstrated. This study confirmed the results of the British Empire study 35 years earlier which apparently went unheeded [8]. Subsequently another 4 studies from Europe were published examining low dose prednisone versus placebo in early RA showing similar results including less joint damage [1619]. These studies also demonstrated that low dose prednisone augmented the effectiveness of dmards like methotrexate. These studies utilized low single morning doses of $5 \mathrm{mg}, 7.5 \mathrm{mg}$ and $10 \mathrm{mg}$ per day for 2 years and each proved effective. Likewise, these doses were safe compared to placebo [20]. These studies confirmed the effectiveness and safety of low morning doses of prednisone.

During the same time a number of studies appeared describing the molecular mechanism of action of glucocorticoids as a result of combining with a cytoplasmic receptor and causing a nuclear inhibitory or activation 
effect [21-23]. Among the many effects of glucocorticoids, it is an inhibition of proinflammatory cytokines. There is a diurnal variation in endogenous secretion of cortisol in normal individuals and inRA with the production of cortisol lowest at midnight and highest at 8:00 am [2]. This diurnal effect corresponds with higher Il6, TNF and lymphocytes at the nadir of glucocorticoid production, namely at night. This diurnal effect correlates in active RA patients with more joint pain and stiffness early in the morning. In active RA, the glucocorticoid production cannot keep up with the inflammatory demand, thus there is relative glucocorticoid deficiency [24].

The diurnal effect raised the question of the importance of timing of the prednisone dose. Arvidson studied the relationship of the time of administration of low doses (5 or $7.5 \mathrm{mg}$ ) of prednisone in active RA to the clinical and laboratory response [3]. In 13 patients, the prednisone was given at 7:30 am and the responses were measured 24 hours later. In another 13 patients the prednisone was given at 2:00 am and the responses were measured 5 hours later. The responses measured were morning stiffness, pain, a composite disease activity index (Lansbury index), ESR and Il6. There was a statistically significant improvement in all measures 5 hours after the prednisone dose, but the response was much less when measured 24 hours after the dose.

The observations of Arvidson were pursued by Buttgereit and others who helped develop a new prednisone product which added a coating around the usual prednisone tablet which delays its absorption.This modified release prednisone (mr) was compared with the usual immediate release prednisone (ir) in a paper appearing in Lancet in 2008 [4]. In patients with RA on stable low doses of prednisone, one group was given a similar dose of (mr) prednisone between $10-12 \mathrm{pm}$ which would be released approximately 4 hours later and the control group given a similar dose of (ir) prednisone in the morning. This was a 12 week study with 144 patients in each group. Initially and at 12 weeks the following parameters were measured: morning stiffness (minutes) by diary, pain VAS, DAS 28, HAQ, ESR and Il6. These were measured 24 hours after the ir prednisone and 7 - 8 hours after the mr prednisone. There was a statistically significant reduction of morning stiffness in those on the $\mathrm{mr}$ prednisone. Also the Il6 was significantly reduced. All other measures were comparable. This study was extended in 249 patients to 1 year [25]. The reduction of morning stiffness and Il6 persisted at one year in the $\mathrm{mr}$ prednisone group. After one year, $37 \%$ of this group achieved ACR 20. The adverse events did not differ from the know profile of adverse events for a similar low dose of regular prednisone. From this study, it appears that a single night time low dose of prednisone is similar in efficacy as the single morning low dose that was used in the previously described studies [15-19], but the comparison has not been rigorously studied for effectiveness and safety.

With this information, Horizon Pharma sought and received FDA approval of this product in July 2012. Unfortunately, the study approved by the FDA did not use the appropriate comparison, which should have been delayed action prednisone, Rayos, versus regular prednisone both given at night and the effects measured the next morning. Rayos is now being marketed. Will this product provide a therapeutic advantage? The development of a new prednisone product and the supporting studies have emphasized the importance of the timing of the low dose of prednisone. It is apparent that a nighttime prednisone dose helps morning stiffness. This has been known for many years and some rheumatologists give low doses of prednisone twice a day, with the night dose relieving the morning stiffness as was shown by the Mayo group in the 1950's.

The critical question that must be addressed before this product can be rationally recommended is: What is the measured response in the morning of Rayos $5 \mathrm{mg}$ versus regular prednisone $5 \mathrm{mg}$, both given at night? Is Rayos given at night more effective than an equal dose of regular prednisone given at night? We know low dose prednisone given in the morning is effective in the treatment of early RA. Is prednisone given at night or low doses given twice a day any more effective and equally safe? These important questions must be addressed and the answer will truly allow us to use low doses of prednisone rationally in the treatment of RA. However, with Rayos on the market, it has the potential of capturing some of the regular prednisone market without being proven more effective. The tragedy of this would be an escalation of the health care cost of treating RA at this time, because Rayos is going to be many times the cost of regular prednisone.

\section{CONCLUSION}

In this era of biologics, it must be remembered that probably the most effective, safe, and inexpensive drug that can be used in RA is prednisone. It has taken over 50 years to finally obtain the basic molecular information and the clinical outcome studies to provide the rational to successfully and safely use low doses of prednisone in the treatment of RA. In RA, the endogenous hydrocortisone response to inflammation is inadequate, so the addition of prednisone supplements the bodies own response to inflammation. Low doseprednisone not only controls the symptoms but also limits bony damage. It is also clear that prednisone augments the effect of dmards. The new delayed release prednisone, Rayos, given at night, may be no more effective than regular prednisone given 
at the same time at night, but it does raise the question of the optimal timing of the low doses of prednisone. Should the low dose be given in am, twice a day or at night? It is imperative to answer this question.

\section{REFERENCES}

[1] Physicians Desk Reference (2013) Rayos. A Concise Monograph. http://fda.net/

[2] Buttgereit, F., Doering, G., Schaeffler, A., Witte, S., Sierakowski, S., Gromnica-Ihle, E., et al., (2008) Efficacy of modified-release versus standard prednisone to reduce duration of morning stiffness of the joints in rheumatoid arthritis (Capra-1): A double-blind, randomized controlled trial. The Lancet, 371, 205-214.

doi:10.1016/S0140-6736(08)60132-4

[3] Straub, R.H. and Cutulo, M. (2007) Circadian rhythms in rheumatoid arthritis. Arthritis \& Rheumatism, 56, 399408. doi:10.1002/art.22368

[4] Arvidson, N.G., Gudbjornsson, B., Larsson, A. and Hallgren, R. (1997) The timing of glucocorticoid administration in rheumatoid arthritis. Annals of the Rheumatic Diseases, 56, 27-31. doi:10.1136/ard.56.1.27

[5] Hench, P.S., Kendall, E.C., Slocumb, C.H. and Polley, H.F. (1949) The effect of a hormone of the adrenal cortex (17-hydroxy-11-dehydrocorticosterone: Compound E) and of pituitary adrenocorticotropic hormone on rheumatoid arthritis. Proceedings of the Staff Meetings of the Mayo Clinic, 24, 181-197.

[6] Ward, L.M., Slocumb, C.H., Polley, H.F., Lowman, E.W. and Hench, P.S. (1951) Clinical effects of cortisone administered orally to patients with rheumatoid arthritis. Proceedings of the Staff Meetings of the Mayo Clinic, 26, 361-370.

[7] Ward, L.M., Polley, H.F., Power, M.H., Mason, H.L., Slocumb, C.H. and Hench, P.S. (1958) Prednisone in rheumatoid arthritis: Metabolic and clinical effects. Annals of the Rheumatic Diseases, 17, 145-159. doi:10.1136/ard.17.2.145

[8] Report by the Joint Committee of the Medical Research Council and Nuffield Foundation on Clinical Trials of Cortisone, ACTH, and other Therapeutic Measures in Chronic Rheumatic Diseases (1959) A comparison of prednisolone with aspirin or other analgesics in the treatment of rheumatoid arthritis. Annals of the Rheumatic Diseases, 18, 173-188. doi:10.1136/ard.18.3.173

[9] Harter, J.G., Reddy, W.J. and Thorn, G.W. (1963) Studies on an intermittent corticosteroid dosage regimen. The New England Journal of Medicine, 269, 591-596. doi:10.1056/NEJM196309192691201

[10] Black, R.L. (1966) The use of synthetic corticosteroids in rheumatoid arthritis. In: Hollander, J.L., Ed., Arthritis and Allied Conditions, 7th Edition, Lea and Febiger, Philadelphia, 364-380.

[11] Hess, E.V. and Goldman, J.A. (1972) Corticosteroids and corticotropin in the therapy of rheumatoid arthritis. In: Hollander, J.L. and McCarty, D.J., Eds., Arthritis and Allied Conditions, 8th Edition, Lea and Febiger, Philadel- phia, 495-516.

[12] Lightfoot Jr., R.W. (1979) Treatment of rheumatoid arthritis. In: McCarty, D.J., Ed., Arthritis and Allied Conditions, 9th Edition, Lea and Febiger, Philadelphia, 513-518.

[13] Ruddy (1985) The management of rheumatoid arthritis. In: Kelley, W.N., Harris Jr., E.D., Ruddy, S. and Sledge, C.B., Eds., Textbook of Rheumatology, 2nd Edition, W.B. Saunders Company, Philadelphia, 979-992.

[14] Harris Jr., E.D. (1993) The management of rheumatoid arthritis. In: Kelley, W.N., Harris Jr., E.D., Ruddy, S. and Sledge, C.B., Eds., Textbook of Rheumatology, 4th Edition, W.B. Saunders Company, Philadelphia, 912-923.

[15] Kirwan, J.R. (1995) The effect of glucocorticoids on joint destruction in rheumatoid arthritis: the arthritis and rheumatism council low-dose glucocorticoid study group. The New England Journal of Medicine, 333, 142-146. doi:10.1056/NEJM199507203330302

[16] van Everdingen, A.A., Jacobs, J.W.G., Siewertsz van Reesema, D.R. and Bijlsma, W.J. (2002) Low-dose prednisone therapy for patients with early active rheumatoid arthritis: Clinical efficacy, disease- modifying properties, and side effects. Annals of Internal Medicine, 136, 1-12. doi:10.7326/0003-4819-136-1-200201010-00006

[17] Svensson, B., Boonen, A., Albertsson, K., van der Heijde, D., Keller, C. and Hafstrom, I. (2005) Low-dose prednisolone in addition to the initial diesease-modifying antirheumatic drug in patients with early active rheumatoid arthritis reduces joint destruction and increases the remission rate. Arthritis \& Rheumatism, 52, 3360-3370. doi:10.1002/art.21298

[18] Wassenberg, S., Rau, R., Steinfeld, P. and Zeidler, H. (2005) Very low-dose prednisolone in early rheumatoid arthritis retards radiographic progression over two years. Arthritis \& Rheumatism, 52, 3371-3380. doi:10.1002/art.21421

[19] Bakker, M., Jacobs, J.W.G., Weising, P.M.J., Verstappen, SMM, Tekstra, J., Ton, E., et al. (2012) Low-dose prednisone inclusion in methotrexate-based tight control strategy for early rheumatoid arthritis. Annals of Internal Medicine, 156, 329-339. doi:10.7326/0003-4819-156-5-201203060-00004

[20] Da Silva, J.A.P., Jacobs, J.W.G., Kirwan, J.R., Boers, M., Saag, K.G., Ines, L.B.S., et al. (2006) Safety of low dose glucocorticoid treatment in rheumatoid arthritis: Published evidence and prospective trial data. Annals of the Rheumatic Diseases, 65, 285-293. doi:10.1136/ard.2005.038638

[21] Buttgereit, F., Straub, R.H., Wehling, M. and Burmester, G.R. (2004) Glucocorticoids in the treatment of rheumatic diseases. Arthritis \& Rheumatism, 50, 3408-3417. doi:10.1002/art.20583

[22] Cidlowski, J.A. (2005) Antiinflammatory action of glucocorticoids-New mechanisms for old drugs. The New England Journal of Medicine, 353, 1711-1723. doi:10.1056/NEJMra050541

[23] Chrousos, G.P. (2009) The hypothalamic-pituitary-adrenal axis and immune-mediated inflammation. The New England Journal of Medicine, 332, 1351-1362.

[24] Straub, R.H., Paimela, L., Peltomaa, R., Scholmerich, J. 
and Leirisalo-Repo, M. (2002) Inadequate low serum levels of steroid hormones in relation to interleukin-6 and tumor necrosis factor in untreated patients with early rheumatoid arthritis and reactive arthritis. Arthritis \& Rheumatism, 46, 654-662. doi:10.1002/art.10177
[25] Buttgereit, F., Hehta, D., Kirwan, J., Szechinski, J., Boers, M., Alten, R., et al. (2013) Low-dose prednisone chronotherapy for rheumatoid arthritis: A randomized clinical trial (Capra-2). Annals of the Rheumatic Diseases, 72, 204-210. doi:10.1136/annrheumdis-2011-201067 